\title{
An update on radiomics techniques in primary liver cancers
}

\author{
Vincenza Granata ${ }^{1 *}$, Roberta Fusco ${ }^{2}$, Sergio Venazio Setola ${ }^{1}$, Igino Simonetti ${ }^{1}$, Diletta Cozzi ${ }^{3,4}$, Giulia Grazzini $i^{3,4}$, \\ Francesca Grassi ${ }^{5}$, Andrea Belli ${ }^{6}$, Vittorio Miele ${ }^{3,4}$, Francesco Izzo ${ }^{6}$ and Antonella Petrillo ${ }^{1}$
}

\begin{abstract}
Background: Radiomics is a progressing field of research that deals with the extraction of quantitative metrics from medical images. Radiomic features detention indirectly tissue features such as heterogeneity and shape and can, alone or in combination with demographic, histological, genomic, or proteomic data, be used for decision support system in clinical setting.
\end{abstract}

Methods: This article is a narrative review on Radiomics in Primary Liver Cancers. Particularly, limitations and future perspectives are discussed.

Results: In oncology, assessment of tissue heterogeneity is of particular interest: genomic analysis have demonstrated that the degree of tumour heterogeneity is a prognostic determinant of survival and an obstacle to cancer control. Therefore, that Radiomics could support cancer detection, diagnosis, evaluation of prognosis and response to treatment, so as could supervise disease status in hepatocellular carcinoma (HCC) and Intrahepatic Cholangiocarcinoma (ICC) patients. Radiomic analysis is a convenient radiological image analysis technique used to support clinical decisions as it is able to provide prognostic and / or predictive biomarkers that allow a fast, objective and repeatable tool for disease monitoring.

Conclusions: Although several studies have shown that this analysis is very promising, there is little standardization and generalization of the results, which limits the translation of this method into the clinical context. The limitations are mainly related to the evaluation of data quality, repeatability, reproducibility, overfitting of the model.

Trial registration: Not applicable.

Keywords: Radiomics, Texture analysis, Machine learnings, Hepatocellular carcinoma, Cholangiocarcinoma

\section{Introduction}

Radiomics is an emerging field that extracts and analyses data from medical images, comprising quantitative and qualitative features not detected by human eye [1-6]. The Radiomics analysis includes several moments: image acquisition (all radiological or nuclear medicine procedures are involved); the segmentation of volume

\footnotetext{
*Correspondence: v.granata@istitutotumori.na.it

1 Division of Radiology, "Istituto Nazionale Tumori IRCCS Fondazione Pascale - IRCCS di Napoli", Via Mariano Semmola 80131, Naples, Italy

Full list of author information is available at the end of the article
}

of interest by automatic, semi-automatic or manual segmentation tools; features creation; database improvement; database analysis with the construction of a predictive model and the validation of the models created and Radiomics signature [7-15].

The features can be morphological, of First-, Secondand Higher-ordes. Morphological ones describe the shape of the traced region of interest (ROI) and its geometric properties such as volume, maximum diameter along different orthogonal directions, maximum surface, tumour compactness, and sphericity. First-order statistics

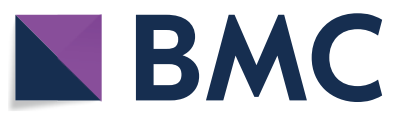

(C) The Author(s) 2022. Open Access This article is licensed under a Creative Commons Attribution 4.0 International License, which permits use, sharing, adaptation, distribution and reproduction in any medium or format, as long as you give appropriate credit to the original author(s) and the source, provide a link to the Creative Commons licence, and indicate if changes were made. The images or other third party material in this article are included in the article's Creative Commons licence, unless indicated otherwise in a credit line to the material. If material is not included in the article's Creative Commons licence and your intended use is not permitted by statutory regulation or exceeds the permitted use, you will need to obtain permission directly from the copyright holder. To view a copy of this licence, visit http://creativecommons.org/licenses/by/4.0/. The Creative Commons Public Domain Dedication waiver (http://creativeco mmons.org/publicdomain/zero/1.0/) applies to the data made available in this article, unless otherwise stated in a credit line to the data. 
features describe the distribution of individual voxel values without concern for spatial relationships.

These are properties based on the histogram that report the average, median, maximum and minimum values of the intensity of the voxels, their asymmetry (asymmetry), kurtosis (flatness), uniformity and entropy. Second-order statistical characteristics include structural characteristics, which are obtained by calculating statistical interrelationships between neighboring voxels and provide a measure of the spatial arrangement of the voxel intensities. Higher-order statistical characteristics are obtained with statistical methods after applying filters or mathematical transformations to images such as fractal analysis, Minkowski functional, wavelet transforms and Laplacian transforms of Gaussian filtered images [16-22].

Clinical, pathological and genomic relationships are established for the predictive model. Therefore, this analysis allows the integration of radiomic characteristics and molecular, clinical or other data of the patient allowing to obtain precision medical instruments [20-23].

Today, the main relevance area is oncological setting, since Radiomics features, providing data on tumour or tissue microenvironment, could be associated with histological grade, prognosis, response to therapy, and survival in innumerable cancers [22, 24-31]. The possibility to combine radiomics with genomic data ("radiogenomics") could theoretically offer the highest level of personalized risk patients stratification so that to greatly augment patient selection for different cancer therapy [32-40].

With the development of the deep learning (DL) technique, the neural network is more commonly used in radiomics studies, and has achieved expert-level performance in several tumours [41-45]. DL self-learning quantitative features may supplement unrevealed imaging features besides conventional radiomic features to improve the predictive power. Additionally, DL-based radiomics avoided time-consuming $[45,46]$.

Recently, it has been a significant increase in the radiomics investigation in liver disease, including liver fibrosis assessment, characterization of malignant and benign lesions, and prognosis [47-49].

\section{Methods}

This article is a narrative review on Radiomics in Primary Liver Cancers. Particularly, limitations and future perspectives are discussed.

\section{Results}

Radiomics: Basic principles and process

Radiomic is planned to be utilised in precision medicine decision support, employing standard of care images that are usually obtained in clinical setting [50-53]. Moreover, Radiomics offers prognostic biomarker which allow for a fast, low-cost, and repeatable means for longitudinal analysis [54-56]. Radiomics is based on the features extraction from medical images, [57-60]. Images assessed during this analysis are accumulated from different centers or data-centers; so, these images could be obtained employing different manufacturers, with diverse protocols and parameters. These elements could influence radiomic models [61, 62].

Segmentation phase is a crucial moment since features are obtained from the segmented volumes. This step is difficult since several lesions have unclear borders and could soffer of high inter-reader variability. However, several researches believe that this approach by expert operator should be chosen even if it is time consuming and not always feasible due to very large data sets to analyse [63]. Automatic and semi-automatic approaches have been developed. Common requirements include maximum automaticity with minimum operator interaction, time efficiency, accuracy, and boundary reproducibility. Several algorithms rely on region-growing methods that require an operator to select a seed point within the volume of interest [63].

Generation of features refers to the extraction of Semantic Features such as dimension, necrosis, margin, location or extraction of non semantic features such as shape, histogram or texture [63-69].

Texture analysis (TA) has sparked interest in the clinical setting as it has proven to be a substantial computerassisted diagnostic tool [70-72]. TA could be defined as the spatial arrangement of models that provides the visual aspect of coarseness, randomness, smoothness. The use of TA compromises the classification and segmentation of the target area, involving a six-step method: image acquisition, definition of the region of interest (ROI), ROI pre-processing, feature extraction, feature selection and classification [70-72]. Manual ROI delineation is still considered the preferred approach. The size of the ROI should be large enough to get the plot data thereby producing statistical significance. It has been established that some characteristics are related such as texture and ROI characteristics, such as mean intensity and variance [73-77].

Feature extraction is the main step in TA indicating the computation of texture features from predefined ROIs. Several methods have been offered, including 2D methods or 3D approaches. Application of 4D TA is promising by including the temporal dimension available in some MRI datasets [78-81].

Radiomic analysis should be performed with large data sets to obtain high statistical power [82-87]. We often have datasets with a large number of features 
extracted from images with a low number of cases. Often many of the characteristics extracted are redundant, non-informative and not useful in the database. Therefore, initial analyzes should include dimensionality reduction and feature selection, generally achieved through unsupervised approaches; and association analysis with one or more specific outcomes using supervised approaches. The two most commonly used unsupervised methods are cluster analysis and principal component analysis (PCA). All selected features that are considered reproducible, informative, and nonredundant can then be used for association analysis. Supervised multivariate analysis consists of building a mathematical model to predict a result or a response variable. The different analysis approaches depend on the purpose of the study and the category of results ranging from statistical methods to data mining / machine learning approaches, such as random forests, neural networks, linear regression, logistic regression, absolute minimum shrinkage and selection operator, and Cox proportional hazards regression [88-92]. Furthermore, since models must be validated to be preferably run on outpatient and independent patient groups, comparability of features extracted from images with different parameters and segmented with different techniques is challenging and can affect the final performance of the model itself [92].

Figure 1 reports a graphic representation of the workflow for extraction of radiomic features from clinical images.

\section{Current applications \\ Clinical setting}

Primary liver cancer, including hepatocellular carcinoma (HCC), intrahepatic cholangiocarcinoma (ICC) and other rare types, is the sixth most usually detected tumour and the third leading cause of tumour death worldwide. HCC may be noninvasively diagnosed by imaging findings alone, often without biopsy. Several morphological and functional data obtained during imaging studies allow a truthful ICC diagnosis.

The choice of modality (CT, US/CEUS or MRI) is correlated to patient, department, and regional features [50, 51, 51, 93-106].

Radiomics is a promising tool in the assessment of HCC (Fig. 2) and ICC patients (Fig. 3).

\section{HCC and radiomics}

Up to now, several researches have assessed radiomics or radiogenomics features as biomarkers in HCC patients, evaluating correlation with response and/or recurrence after several treatments as chemotherapy, resection, ablation therapies, and transplantation. The main diagnostic tool used in radiomics studies has been Computed Tomography (CT) [107]. Otherwise, few researches have assessed radiomics data obtained by Magnetic Resonance Imaging (MRI). This may be due to the difficulty of providing standardization of $M R$ sequences respect to $C T$ [23, 108, 109]. In fact, MRI offers the advantage of high contrast resolution and functional data, and this tool is superior in the assessment of tumour metabolism.

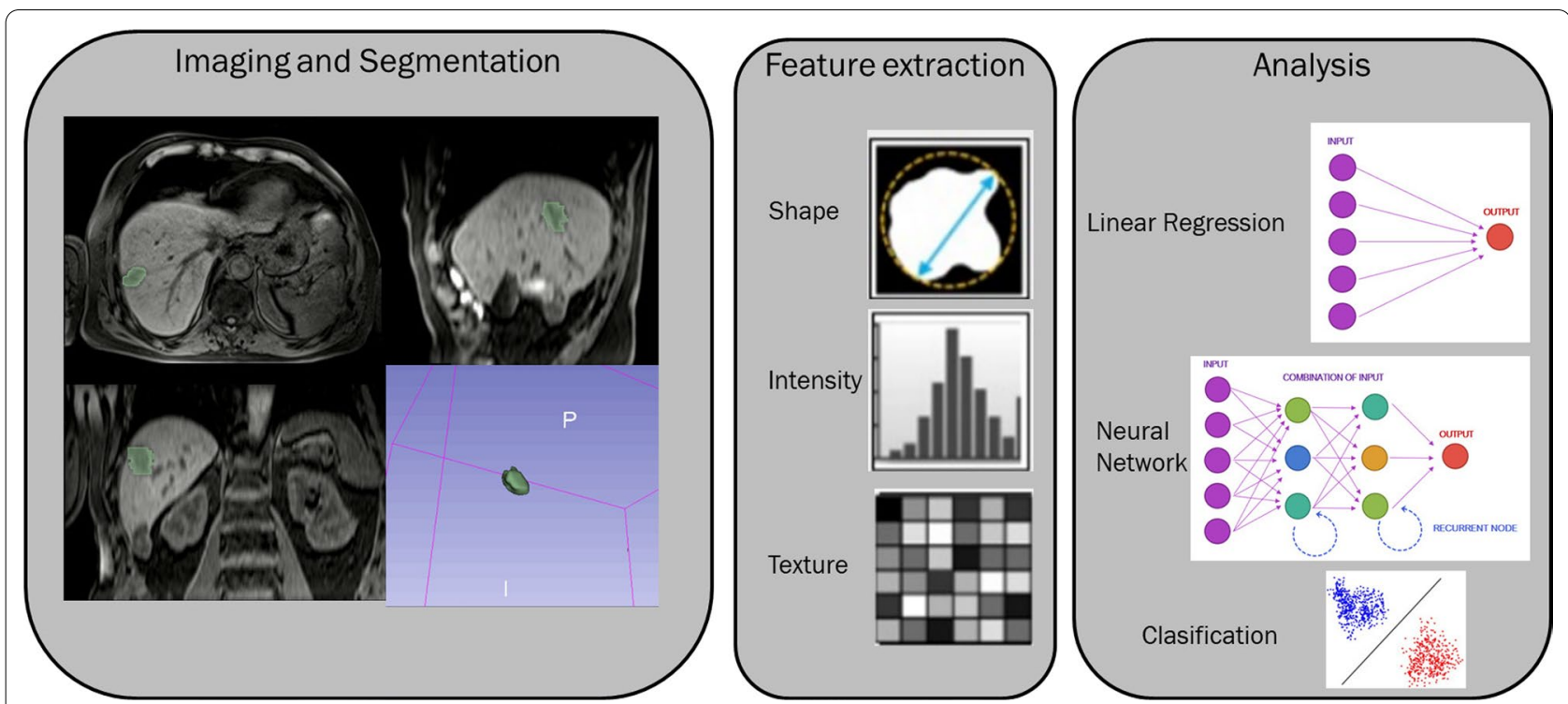

Fig. 1 Workflow for extraction of radiomic features from clinical images. The first step contains receiving images and segmentation of the region of interest. The next step is feature extraction within the defined ROI. In the last step the features are analysed, and combined and compared with clinical data 


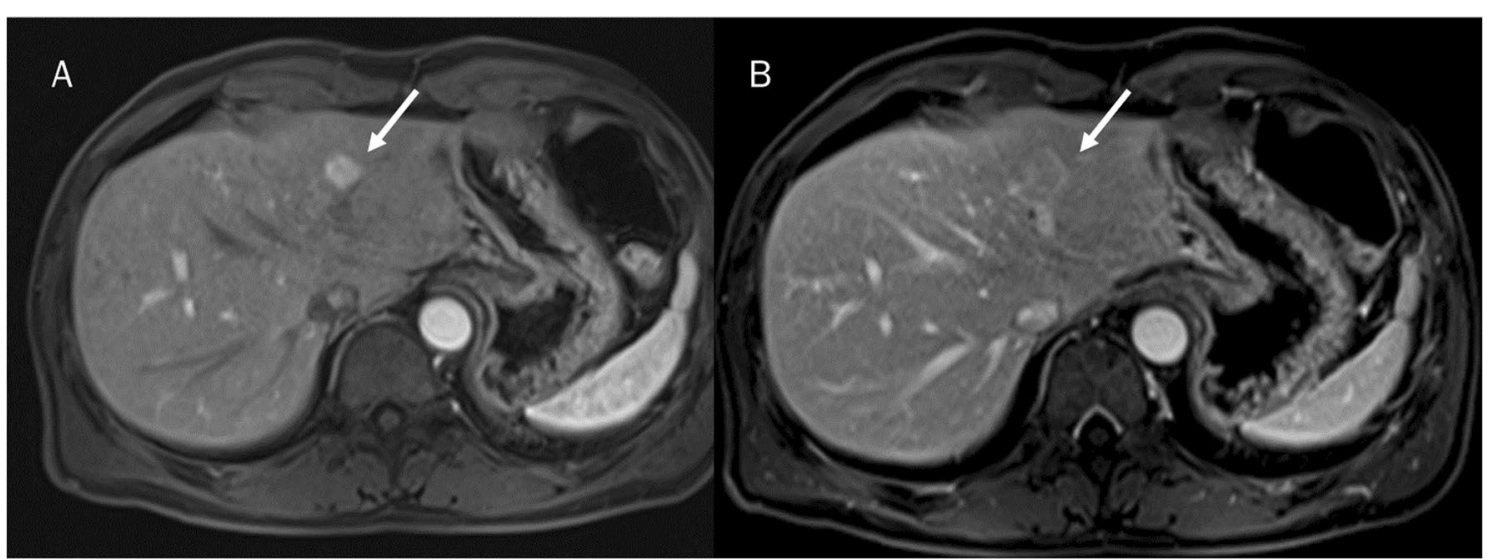

Fig. 2 HCC on II liver segment assessed by MRI. In A, arterial phase, the arrow shows lesion arterial hyperenhancement. In B, portal phase of contrast study, the arrow shows lesion wash-out and capsule appearance

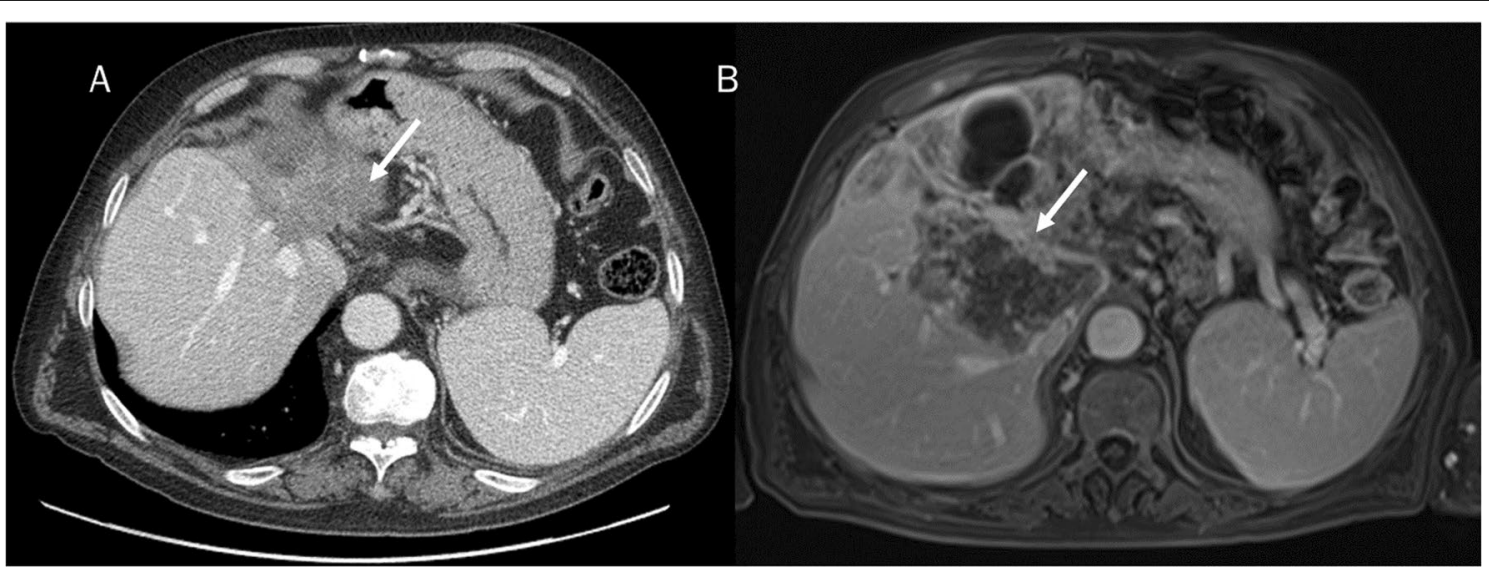

Fig. 3 ICC on II-IV hepatic segment assessed by CT (A) and MRI (B). The lesion shows peripheral rim hyperenhancement with progressive contrast enhancement (arrow)

The areas of main attention have been correlated to lesion characterization and treatment evaluation [107, 110-135].

For differentiation between $\mathrm{HCC}$ and benign liver lesions, a CT radiomic nomogram demonstrated an area under the receiver operating characteristic curve (AUC) of 0.917 to differentiate focal nodular hyperplasia (FNH) by HCC [129]. An MRI reported an AUC of 0.89 (sensitivity 0.822 , specificity 0.714 ) to differentiate HCC by haemangioma using conventional and diffusion sequences (DWI) [130]. Furthermore, using CT and MRI, fusion models showed an AUC of 0.966 for CT and 0.971 for MRI to differentiate HCC by FNH [131]. Furthermore, a retrospective multicenter cohort study of 178 patients with cirrhosis showed an AUC of 0.66 in the diagnosis of HCC, demonstrating the advantage of Artificial Intelligence (AI) to improve physician decisions identifying high risk of HCC patients [188].
Oyama et al. evaluated MRI radiomics features for liver tumor classification using TA and topological data analysis demonstrating that TA could provide useful data for diagnosing liver disease [136]. $\mathrm{Li}$ et al. assessed the TA feasibility based on the recovery of attenuated spectral inversion on MRI for the classification of hepatic haemangioma $(\mathrm{HH})$, liver metastases (HM), and hepatocellular carcinoma $(\mathrm{HCC})$, demonstrating that $\mathrm{HH}$ versus $\mathrm{HM}, \mathrm{HM}$ versus $\mathrm{HCC}$ and $\mathrm{HH}$ and $\mathrm{HCC}$ could be differentiated by 9,16 and 10 TA features, respectively [137]. Jansen et al. assessed MRI datasets of 125 benign lesions (40 adenomas, 29 cysts and 56 haemangiomas) and 88 malignant lesions (30 HCC and 58 metastases). Contrast curve, grey level histogram, and grey level co-occurrence matrix texture features were extracted from the DCEMRI and T2- W images. In addition, risk factors including the presence of steatosis, cirrhosis, and a known primary tumour were used as features. Fifty features with 
the highest ANOVA F- score were selected and fed to a randomized trees classifier. The classifier evaluation was performed using the leave-one-out cross validation and ROC curve analysis was performed. They demonstrated that the overall accuracy for the classification of the five main types of focal liver disease is 0.77 . Sensitivity / specificity is $0.80 / 0.78,0.93 / 0.93,0.84 / 0.82,0.73 / 0.56$ and 0.62/0.77 for adenoma, cyst, haemangioma, hepatocellular carcinoma and metastases [138], respectively. These data are similar to the data by Gatos et al. [139].

Different researches have suggested the use of radiomic parameters to guide therapeutic decisions by response prediction of ablative therapies and immuno-oncological characteristics [124-126]. Therefore, if the therapeutic direction is considered inappropriate for ablation treatment, it should be changed with the targeted molecular agents use. However, the clinical benefit of radiomic features should been validated by further studies in a prospective setting.

\section{ICC and radiomics}

Many studies have been assessed the radiomics or radiogenomics role in ICC [140-166]. The main interest area has been the assessment of recurrence after surgical resection.

Chu et al. [140] assessed 203 ICCs, that were subdivided into training and the validation set. Clinical features and radiomic features were used with a random forest algorithm and logistic models to build both a clinical model and a radiomic model. The radiomic model showed a higher AUC than the clinical model to predict avoidable resections in ICC reaching a sensitivity of 0.846 and a specificity of 0.771 in the validation cohort [140]. Quin et al. [141] developed a multilevel model, integrating clinicopathology, molecular pathology and radiology to predict early recurrence after curative surgery, using a machine-learning analysis of 18,120 radiomic features based on CT studies and 48 clinical features. They demonstrated that the radiomics based multilevel model has superior performance over conventional staging systems and could serve as a prognostic tool for planning surveillance and guiding individualized post-operative management [141]. Also Hao et al. [142] developed a non-invasive $\mathrm{CT}$ based radiomics analysis model to predict early recurrence in 177 ICC patients. Radiomic features were extracted on six established radiomic models were selected as stable according to the robustness-based rule. Max-Relevance Min-Redundancy (MRMR) combined with Gradient Boosting Machine (GBM) produced the highest AUCs of 0.802 and 0.781 in the training and testing set, respectively [142].

Mosconi et al. [150] evaluated the relationships between the structural features of CT before TARE and objective response (OR), progression-free survival (PFS) and overall survival (OS). They demonstrated that iCCs showing OR after TARE had higher contrast iodine uptake in the arterial phase (higher mean histogram values, $p<0.001$ ) and a more homogeneous distribution (lower kurtosis, $p=0.043$; GLCM contrast, $p=0.004$; GLCM dissimilarity, $p=0.005$ and higher GLCM homogeneity, $p=0.005$ and GLCM correlation $p=0.030$ ) on pre-TARE CT. A favourable radiomic signature was calculated and observed in 15 of the 55 patients [150].

\section{Current limitations}

To day, radiomics researches are in their immaturity with no standardized or unified standards for this problematic analysis. Though several researches reported meticulously manual segmentation, however, automated segmentation algorithms should be employed for realising standardization. In addition, the absence of clear definition of reason for false-positive results in Convolutional Neural Network still an important issue. In addition, for ROI selection, there is no appropriate algorithm to segment tumour area. Another critical issue is the lack of standardization in results reporting that makes it confusing for readers. It may be appropriate report features according to 'Image biomarker standardisation initiative' using formal lexicon.

With regard to machine-learning algorithms, these are different in different studies since there is no research to prove which algorithm is the main suitable considering the study type. Finally, most of the current research results are still in the training sample stage, so the model's high accuracy does not reflect its actual predictive ability. Whether the model is really effective or not depends on the validation phase by the test sample.

\section{Discussion and Conclusions}

Radiomics is a rapidly evolving field of research that deals with the extraction of quantitative metrics within medical images that capture tissue and lesion characteristics such as heterogeneity and shape and which can, alone or in combination with demographic, histological, genomic or proteomic data, to be used for the resolution of clinical problems. In oncology, the assessment of tissue heterogeneity is of particular interest: genomic analyzes have shown that the degree of tumour heterogeneity is a prognostic determinant of survival.

Although many studies have shown that radiomics to be very promising, there has been little standardization and generalization of radiomic findings, which limit the use of this method into the clinical practice. Clear limitations especially regard to data quality control, repeatability, reproducibility, generalizability of results and issues related to model overfitting. 


\section{Acknowledgements}

The authors are grateful to Alessandra Trocino, librarian at the National Cancer Institute of Naples, Italy.

\section{Authors' contributions}

The authors confirm that the article is not under consideration for publication elsewhere. Each author has participated sufficiently to take public responsibility for the manuscript content. All authors read and approved the final manuscript.

\section{Funding}

No funding

\section{Availability of data and materials}

Data are available at https://zenodo.org/record/6307725\#.Yhz8VOjMK3A.

\section{Declarations}

Ethics approval and consent to participate

Not applicable.

\section{Consent for publication}

Not applicable.

\section{Competing interests}

The authors declare that they have no competing interests.

\section{Author details}

'Division of Radiology, "Istituto Nazionale Tumori IRCCS Fondazione Pascale - IRCCS di Napoli", Via Mariano Semmola 80131, Naples, Italy. ${ }^{2}$ Medical Oncology Division, Igea SpA, Napoli, Italy. ${ }^{3}$ Department of Radiology, Azienda Ospedaliero-Universitaria Careggi, Florence, Italy. ${ }^{4}$ Italian Society of Medical and Interventional Radiology (SIRM), SIRM Foundation, Via Della Signora 2, 20122 Milan, Italy. ${ }^{5}$ Division of Radiology, "Università Degli Studi Della Campania Luigi Vanvitelli", Naples, Italy. ${ }^{6}$ Division of Hepatobiliary Surgical Oncology, "Istituto Nazionale Tumori IRCCS Fondazione Pascale - IRCCS di Napoli", 80131 Naples, Italy.

\section{Received: 19 February 2022 Accepted: 28 February 2022} Published online: 04 March 2022

\section{References}

1. Lambin P, Leijenaar RTH, Deist TM, Peerlings J, de Jong EEC, van Timmeren J, Sanduleanu S, Larue RTHM, Even AJG, Jochems A, van Wijk Y, Woodruff H, van Soest J, Lustberg T, Roelofs E, van Elmpt W, Dekker A, Mottaghy FM, Wildberger JE, Walsh S. Radiomics: the bridge between medical imaging and personalized medicine. Nat Rev Clin Oncol. 2017;14(12):749-62.

2. Limkin EJ, Sun R, Dercle L, Zacharaki El, Robert C, Reuzé S, Schernberg A, Paragios N, Deutsch E, Ferté C. Promises and challenges for the implementation of computational medical imaging (radiomics) in oncology. Ann Oncol. 2017;28(6):1191-206.

3. Verma V, Simone CB 2nd, Krishnan S, Lin SH, Yang J, Hahn SM. The rise of radiomics and implications for oncologic management. J Natl Cancer Inst. 2017;109(7).

4. Agazzi GM, Ravanelli M, Roca E, Medicina D, Balzarini P, Pessina C, Vermi W, Berruti A, Maroldi R, Farina D. CT texture analysis for prediction of EGFR mutational status and ALK rearrangement in patients with non-small cell lung cancer. Radiol Med. 2021. https://doi.org/10.1007/ s11547-020-01323-7.

5. Palumbo P, Masedu F, De Cataldo C, Cannizzaro E, Bruno F, Pradella S, Arrigoni F, Valenti M, Splendiani A, Barile A, Giovagnoni A, Masciocchi C, Di Cesare E. Real-world clinical validity of cardiac magnetic resonance tissue tracking in primitive hypertrophic cardiomyopathy. Radiol Med. 2021;126(12):1532-43. https://doi.org/10.1007/s11547-021-01432-x (Epub 2021 Dec 11).

6. Andrisani MC, Vespro V, Fusco S, Palleschi A, Musso V, Esposito A, Coppola A, Spadafora P, Damarco F, Scaravilli V, Cortesi L, Scudeller L, Larici
AR, Carrafiello G. Interobserver variability in the evaluation of primary graft dysfunction after lung transplantation: impact of radiological training and analysis of discordant cases. Radiol Med. 2021. https://doi. org/10.1007/s11547-021-01438-5.

7. Santone A, Brunese MC, Donnarumma F, Guerriero P, Mercaldo F, Reginelli A, Miele V, Giovagnoni A, Brunese L. Radiomic features for prostate cancer grade detection through formal verification. Radiol Med. 2021. https://doi.org/10.1007/s11547-020-01314-8.

8. Granata V, Fusco R, Costa M, Picone C, Cozzi D, Moroni C, La Casella GV, Montanino A, Monti R, Mazzoni F, Grassi R, Malagnino VG, Cappabianca S, Grassi R, Miele V, Petrillo A. Preliminary report on computed tomography radiomics features as biomarkers to immunotherapy selection in lung adenocarcinoma patients. Cancers (Basel). 2021;13(16):3992. https://doi.org/10.3390/cancers13163992.

9. Granata V, Fusco R, Barretta ML, Picone C, Avallone A, Belli A, Patrone R, Ferrante M, Cozzi D, Grassi R, Grassi R, Izzo F, Petrillo A. Radiomics in hepatic metastasis by colorectal cancer. Infect Agent Cancer. 2021;16(1):39. https://doi.org/10.1186/s13027-021-00379-y.

10. Fusco R, Piccirillo A, Sansone M, Granata V, Rubulotta MR, Petrosino T, Barretta ML, Vallone P, Di Giacomo R, Esposito E, Di Bonito M, Petrillo A. Radiomics and artificial intelligence analysis with textural metrics extracted by contrast-enhanced mammography in the breast lesions classification. Diagnostics (Basel). 2021;11(5):815. https://doi.org/10. 3390/diagnostics11050815.

11. Fusco R, Granata V, Mazzei MA, Meglio ND, Roscio DD, Moroni C, Monti R, Cappabianca C, Picone C, Neri E, Coppola F, Montanino A, Grassi R, Petrillo A, Miele V. Quantitative imaging decision support $\left(\mathrm{QIDS}^{\mathrm{TM}}\right.$ ) tool consistency evaluation and radiomic analysis by means of 594 metrics in lung carcinoma on chest CT scan. Cancer Control. 2021;28:1073274820985786. https://doi.org/10.1177/1073274820 985786.

12. Granata V, Fusco R, Avallone A, De Stefano A, Ottaiano A, Sbordone C, Brunese L, Izzo F, Petrillo A. Radiomics-derived data by contrast enhanced magnetic resonance in RAS mutations detection in colorectal liver metastases. Cancers (Basel). 2021;13(3):453. https://doi.org/10. 3390/cancers13030453.

13. Granata V, Fusco R, Risi C, Ottaiano A, Avallone A, De Stefano A, Grimm R, Grassi R, Brunese L, Izzo F, Petrillo A. Diffusion-weighted MRI and diffusion kurtosis imaging to detect RAS mutation in colorectal liver metastasis. Cancers (Basel). 2020;12(9):2420. https://doi.org/10.3390/ cancers12092420.

14. Petralia G, Summers PE, Agostini A, Ambrosini R, Cianci R, Cristel G, Calistri L, Colagrande S. Dynamic contrast-enhanced MRI in oncology: how we do it. Radiol Med. 2020;125:1288-300. https://doi.org/10.1007/ s11547-020-01220-z.

15. Ria F, Samei E. Is regulatory compliance enough to ensure excellence in medicine? Radiol Med. 2020;125:904-5. https://doi.org/10.1007/ s11547-020-01171-5.

16. Zhang A, Song J, Ma Z, Chen T. Combined dynamic contrast-enhanced magnetic resonance imaging and diffusion-weighted imaging to predict neoadjuvant chemotherapy effect in FIGO stage IB2-IIA2 cervical cancers. Radiol Med. 2020;125:1233-42. https://doi.org/10.1007/ s11547-020-01214-x.

17. Crimi F, Capelli G, Spolverato G, Bao QR, Florio A, Milite Rossi S, Cecchin D, Albertoni L, Campi C, Pucciarelli S, et al. MRI T2-weighted sequencesbased texture analysis (TA) as a predictor of response to neoadjuvant chemo-radiotherapy ( $\mathrm{nCRT}$ ) in patients with locally advanced rectal cancer (LARC). Radiol Med. 2020;125:1216-24. https://doi.org/10.1007/ s11547-020-01215-w.

18. Kirienko M, Ninatti G, Cozzi L, Voulaz E, Gennaro N, Barajon I, Ricci F, Carlo-Stella C, Zucali P, Sollini M, et al. Computed tomography (CT)-derived radiomic features differentiate prevascular mediastinum masses as thymic neoplasms versus lymphomas. Radiol Med. 2020;125:951-60. https://doi.org/10.1007/s11547-020-01188-w.

19. Zhang L, Kang L, Li G, Zhang X, Ren J, Shi Z, Li J, Yu S. Computed tomography-based radiomics model for discriminating the risk stratification of gastrointestinal stromal tumors. Radiol Med. 2020;125:465-73. https:// doi.org/10.1007/s11547-020-01138-6.

20. Gurgitano M, Angileri SA, Rodà GM, Liguori A, Pandolfi M, lerardi AM, Wood BJ, Carrafiello G. Interventional radiology ex-machina: impact of 
artificial intelligence on practice. Radiol Med. 2021;126(7):998-1006. https://doi.org/10.1007/s11547-021-01351-x (Epub 2021 Apr 16).

21. Scapicchio C, Gabelloni M, Barucci A, Cioni D, Saba L, Neri E. A deep look into radiomics. Radiol Med. 2021;126(10):1296-311. https://doi. org/10.1007/s11547-021-01389-x (Epub 2021 Jul 2).

22. Wei J, Jiang H, Gu D, Niu M, Fu F, Han Y, Song B, Tian J. Radiomics in liver diseases: current progress and future opportunities. Liver Int. 2020;40(9):2050-63. https://doi.org/10.1111/liv.14555.

23. Benedetti G, Mori M, Panzeri MM, Barbera M, Palumbo D, Sini C, Muffatti F, Andreasi V, Steidler S, Doglioni C, Partelli S, Manzoni M, Falconi M, Fiorino C, De Cobelli F. CT-derived radiomic features to discriminate histologic characteristics of pancreatic neuroendocrine tumors. Radiol Med. 2021. https://doi.org/10.1007/s11547-021-01333-z.

24. Saini A, Breen I, Pershad Y, Naidu S, Knuttinen MG, Alzubaidi S, Sheth R, Albadawi H, Kuo M, Oklu R. Radiogenomics and radiomics in liver cancers. Diagnostics (Basel). 2018;9(1):4. https://doi.org/10.3390/diagn ostics9010004.

25. de la Pinta C, Castillo ME, Collado M, Galindo-Pumariño C, Peña C. Radiogenomics: hunting down liver metastasis in colorectal cancer patients. Cancers (Basel). 2021;13(21):5547. https://doi.org/10.3390/ cancers 13215547

26. Nardone V, Reginelli A, Grassi R, Boldrini L, Vacca G, D'lppolito E, Annunziata S, Farchione A, Belfiore MP, Desideri I, Cappabianca S. Delta radiomics: a systematic review. Radiol Med. 2021;126(12):1571-83. https://doi.org/10.1007/s11547-021-01436-7.

27. Brunese L, Brunese MC, Carbone M, Ciccone V, Mercaldo F, Santone A. Automatic PI-RADS assignment by means of formal methods. Radiol Med. 2021. https://doi.org/10.1007/s11547-021-01431-y.

28. van der Lubbe MFJA, Vaidyanathan A, de Wit M, van den Burg EL, Postma AA, Bruintjes TD, Bilderbeek-Beckers MAL, Dammeijer PFM, Bossche SV, Van Rompaey V, Lambin P, van Hoof M, van de Berg R. A non-invasive, automated diagnosis of Menière's disease using radiomics and machine learning on conventional magnetic resonance imaging: A multicentric, case-controlled feasibility study. Radiol Med. 2021. https:// doi.org/10.1007/s11547-021-01425-w.

29. Granata V, Fusco R, Avallone A, Cassata A, Palaia R, Delrio P, Grassi R, Tatangelo F, Grazzini G, Izzo F, Petrillo A. Abbreviated MRI protocol for colorectal liver metastases: how the radiologist could work in pre surgical setting. PLOS ONE. 2020;15(11):e0241431. https://doi.org/10.1371/ journal.pone.0241431.

30. Granata V, Fusco R, Venanzio Setola S, Mattace Raso M, Avallone A, De Stefano A, Nasti G, Palaia R, Delrio P, Petrillo A, Izzo F. Liver radiologic findings of chemotherapy-induced toxicity in liver colorectal metastases patients. Eur Rev Med Pharmacol Sci. 2019;23(22):9697-706. https:// doi.org/10.26355/eurrev_201911_19531.

31. Granata V, Fusco R, Maio F, Avallone A, Nasti G, Palaia R, Albino V, Grassi R, Izzo F, Petrillo A. Qualitative assessment of EOB-GD-DTPA and Gd-BT-DO3A MR contrast studies in HCC patients and colorectal liver metastases. Infect Agent Cancer. 2019;14:40. https://doi.org/10.1186/ s13027-019-0264-3.

32. Granata V, Fusco R, de Lutio di Castelguidone E, Avallone A, Palaia R, Delrio P, Tatangelo F, Botti G, Grassi R, Izzo F, Petrillo A. Diagnostic performance of gadoxetic acid-enhanced liver MRI versus multidetector CT in the assessment of colorectal liver metastases compared to hepatic resection. BMC Gastroenterol. 2019;19(1):129. https://doi.org/10.1186/ s12876-019-1036-7.

33. https://pyradiomics.readthedocs.io/en/latest/features.html

34. Zwanenburg A, Vallières $M$, Abdalah MA, Aerts HJWL, Andrearczyk V, Apte A, Ashrafinia S, Bakas S, Beukinga RJ, Boellaard R, et al. The image biomarker standardization initiative: standardized quantitative radiomics for high-throughput im-age-based phenotyping. Radiology. 2020;295:328-38.

35. Granata V, Fusco R, Avallone A, Catalano O, Piccirillo M, Palaia R, Nasti $G$, Petrillo A, Izzo F. A radiologist's point of view in the presurgical and intraoperative setting of colorectal liver metastases. Future Oncol. 2018;14(21):2189-206. https://doi.org/10.2217/fon-2018-0080.

36. Granata V, Fusco R, Catalano O, Avallone A, Palaia R, Botti G, Tatangelo F, Granata F, Cascella M, Izzo F, Petrillo A. Diag-nostic accuracy of magnetic resonance, computed tomography and contrast enhanced ultrasound in radiological multimo-dality assessment of peribiliary liver metastases. PLoS ONE. 2017;12:e0179951.
37. Granata V, Fusco R, Catalano O, Filice S, Amato DM, Nasti G, Avallone A, Izzo F, Petrillo A. Early assessment of colorectal cancer patients with liver metastases treated with antiangiogenic drugs: the role of intravoxel incoherent motion in diffusion-weighted imaging. PLOS ONE. 2015;10:e0142876.

38. Beckers RCJ, Trebeschi S, Maas M, Schnerr RS, Sijmons JML, Beets GL, Houwers JB, Beets-Tan RGH, Lambregts DMJ. CT texture analysis in colorectal liver metastases and the surrounding liver parenchyma and its potential as an imaging biomarker of disease aggressiveness, response and survival. Eur J Radiol. 2018;102:15-21.

39. Andersen IR, Thorup K, Andersen MB, Olesen R, Mortensen FV, Nielsen DT, Rasmussen F. Texture in the monitoring of regorafenib therapy in patients with colorectal liver metastases. Acta Radiol. 2019;60:1084-93.

40. Zhang H, Li W, Hu F, Sun Y, Hu T, Tong T. MR texture analysis: Potential imaging biomarker for predicting the chemotherapeutic response of patients with colorectal liver metastases. Abdom Radiol. 2018;44:65-71.

41. Kirienko M, Ninatti G, Cozzi L, Voulaz E, Gennaro N, Barajon I, Ricci F, Carlo-Stella C, Zucali P, Sollini M, Balzarini L, Chiti A. Computed tomography (CT)-derived radiomic features differentiate prevascular mediastinum masses as thymic neoplasms versus lymphomas. Radiol Med. 2020;125(10):951-60. https://doi.org/10.1007/s11547-020-01188-w.

42. Zhang Y, Zhu Y, Zhang K, Liu Y, Cui J, Tao J, Wang Y, Wang S. Invasive ductal breast cancer: preoperative predict Ki-67 index based on radiomics of ADC maps. Radiol Med. 2020;125(2):109-16. https://doi.org/ 10.1007/s11547-019-01100-1.

43. Zhang L, Kang L, Li G, Zhang X, Ren J, Shi Z, Li J, Yu S. Computed tomography-based radiomics model for discriminating the risk stratification of gastrointestinal stromal tumors. Radiol Med. 2020;125(5):465-73. https://doi.org/10.1007/s11547-020-01138-6.

44. Fusco R, Granata V, Petrillo A. Introduction to special issue of radiology and imaging of cancer. Cancers Basel. 2020;12(9):2665. https://doi.org/ 10.3390/cancers 12092665.

45. Grassi R, Belfiore MP, Montanelli A, Patelli G, Urraro F, Giacobbe G, Fusco R, Granata V, Petrillo A, Sacco P, Mazzei MA, Feragalli B, Reginelli A, Cappabianca S. COVID-19 pneumonia: computer-aided quantification of healthy lung parenchyma, emphysema, ground glass and consolidation on chest computed tomography (CT). Radiol Med. 2020;126:55360. https://doi.org/10.1007/s11547-020-01305-9.

46. Grassi R, Cappabianca S, Urraro F, Feragalli B, Montanelli A, Patelli G, Granata V, Giacobbe G, Russo GM, Grillo A, De Lisio A, Paura C, Clemente A, Gagliardi G, Magliocchetti S, Cozzi D, Fusco R, Belfiore MP, Grassi R, Miele $V$. Chest CT computerized aided quantification of PNEUMONIA lesions in COVID-19 infection: a comparison among three commercial software. Int J Environ Res Public Health. 2020;17(18):6914. https://doi. org/10.3390/ijerph17186914.

47. Liang H, Hu C, Lu J, Zhang T, Jiang J, Ding D, Du S, Duan S. Correlation of radiomic features on dynamic contrast-enhanced magnetic resonance with microvessel density in hepatocellular carcinoma based on different models. J Int Med Res. 2021;49(3):300060521997586. https://doi. org/10.1177/0300060521997586.

48. Sahani DV, Jiang T, Hayano K, Duda DG, Catalano OA, Ancukiewicz M, Jain RK, Zhu AX. Magnetic resonance imaging biomarkers in hepatocellular carcinoma: association with response and circulating biomarkers after sunitinib therapy. J Hematol Oncol. 2013;6:51.

49. Gutmann DAP, Rospleszcz S, Rathmann W, Schlett CL, Peters A, Wachinger C, Gatidis S, Bamberg F. MRI-derived radiomics features of hepatic fat predict metabolic states in individuals without cardiovascular disease. Acad Radiol. 2020;28:S1-10. https://doi.org/10.1016/j.acra.2020. 06.030 .

50. Shin N, Choi JA, Choi JM, Cho ES, Kim JH, Chung JJ, Yu JS. Sclerotic changes of cavernous hemangioma in the cirrhotic liver: long-term follow-up using dynamic contrast-enhanced computed tomography. Radiol Med. 2020;125(12):1225-32. https://doi.org/10.1007/ s11547-020-01221-y.

51. Bottari A, Silipigni S, Carerj ML, Cattafi A, Maimone S, Marino MA, Mazziotti S, Pitrone A, Squadrito G, Ascenti G. Dual-source dualenergy $C T$ in the evaluation of hepatic fractional extracellular space in cirrhosis. Radiol Med. 2020;125(1):7-14. https://doi.org/10.1007/ s11547-019-01089-7.

52. Agostini A, Borgheresi A, Carotti M, Ottaviani L, Badaloni M, Floridi C, Giovagnoni A. Third-generation iterative reconstruction on a 
dual-source, high-pitch, low-dose chest CT protocol with tin filter for spectral shaping at $100 \mathrm{kV}$ : a study on a small series of COVID-19 patients. Radiol Med. 2021;126(3):388-98. https://doi.org/10.1007/ s11547-020-01298-5.

53. Mathew RP, Sam M, Raubenheimer M, Patel V, Low G. Hepatic hemangiomas: the various imaging avatars and its mimickers. Radiol Med. 2020;125(9):801-15. https://doi.org/10.1007/s11547-020-01185-z.

54. Xiang F, Liang X, Yang L, Liu X, Yan S. CT radiomics nomogram for the preoperative prediction of severe post-hepatectomy liver failure in patients with huge $(\geq 10 \mathrm{~cm})$ hepatocellular carcinoma. World I Surg Oncol. 2021;19(1):344. https://doi.org/10.1186/s12957-021-02459.

55. Shi L, He Y, Yuan Z, Benedict S, Valicenti R, Qiu J, Rong Y. Radiomics for response and outcome assessment for non-small cell lung cancer. Technol Cancer Res Treat. 2018;17:1533033818782788.

56. Jia TY, Xiong JF, Li XY, Yu W, Xu ZY, Cai XW, Ma JC, Ren YC, Larsson R, Zhang J, Zhao J, Fu XL. Identifying EGFR mutations in lung adenocarcinoma by noninvasive imaging using radiomics features and random forest modeling. Eur Radiol. 2019;29(9):4742-50. https://doi.org/10. 1007/s00330-019-06024-y.

57. Yin Q, Hung SC, Rathmell WK, Shen L, Wang L, Lin W, Fielding JR, Khandani AH, Woods ME, Milowsky MI, Brooks SA, Wallen EM, Shen D. Integrative radiomics expression predicts molecular subtypes of primary clear cell renal cell carcinoma. Clin Radiol. 2018;73(9):782-91. https://doi.org/10.1016/j.crad.2018.04.009.

58. Cusumano D, Meijer G, Lenkowicz J, Chiloiro G, Boldrini L, Masciocchi C, Dinapoli N, Gatta R, Casà C, Damiani A, Barbaro B, Gambacorta MA, Azario L, De Spirito M, Intven M, Valentini V. A field strength independent MR radiomics model to predict pathological complete response in locally advanced rectal cancer. Radiol Med. 2020. https://doi.org/10 1007/s11547-020-01266-z.

59. Wei J, Cheng J, Gu D, Chai F, Hong N, Wang Y, Tian J. Deep learningbased radiomics predicts response to chemotherapy in colorectal liver metastases. Med Phys. 2020. https://doi.org/10.1002/mp.14563.

60. Granata V, Grassi R, Fusco R, Izzo F, Brunese L, Delrio P, Avallone A, Pecori B, Petrillo A. Current status on response to treatment in locally advanced rectal cancer: what the radiologist should know. Eur Rev Med Pharmacol Sci. 2020;24(23):12050-62. https://doi.org/10.26355/eurrev_ 202012.

61. Sansone M, Grassi R, Belfiore MP, Gatta G, Grassi F, Pinto F, La Casella GV, Fusco R, Cappabianca S, Granata V, Grassi R. Radiomic features of breast parenchyma: assessing differences between for processing and for presentation digital mammography. Insights Imaging. 2021;12(1):147. https://doi.org/10.1186/s13244-021-01093-4.

62. Granata V, Fusco R, Sansone M, Grassi R, Maio F, Palaia R, Tatangelo F, Botti G, Grimm R, Curley S, Avallone A, Izzo F, Petrillo A. Magnetic resonance imaging in the assessment of pancreatic cancer with quantitative parameter extraction by means of dynamic contrast-enhanced magnetic resonance imaging, diffusion kurtosis imaging and intravoxel incoherent motion diffusion-weighted imaging. Therap Adv Gastroenterol. 2020;13:1756284819885052. https://doi.org/10.1177/1756284819 885052.

63. Rizzo S, Botta F, Raimondi S, Origgi D, Fanciullo C, Morganti AG, Bellomi M. Radiomics: the facts and the challenges of image analysis. Eur Radiol Exp. 2018;2(1):36. https://doi.org/10.1186/s41747-018-0068-z.

64. Granata V, Grassi R, Fusco R, Belli A, Cutolo C, Pradella S, Grazzini G, La Porta M, Brunese MC, De Muzio F, Ottaiano A, Avallone A, Izzo F, Petrillo A. Diagnostic evaluation and ablation treatments assessment in hepatocellular carcinoma. Infect Agent Cancer. 2021;16(1):53. https:// doi.org/10.1186/s13027-021-00393-0.

65. Fusco R, Grassi R, Granata V, Setola SV, Grassi F, Cozzi D, Pecori B, Izzo F, Petrillo A. Artificial intelligence and COVID-19 using chest CT scan and chest X-ray images: machine learning and deep learning approaches for diagnosis and treatment. J Pers Med. 2021;11(10):993. https://doi. org/10.3390/jpm11100993.

66. Granata V, Fusco R, Filice S, Catalano O, Piccirillo M, Palaia R, Izzo F, Petrillo $\mathrm{A}$. The current role and future prospectives of functional parameters by diffusion weighted imaging in the assessment of histologic grade of HCC. Infect Agent Cancer. 2018;13:23. https://doi.org/10.1186/ s13027-018-0194-5.

67. Granata V, Fusco R, Avallone A, Catalano O, Filice F, Leongito M, Palaia R, Izzo F, Petrillo A. Major and ancillary magnetic resonance features of
LI-RADS to assess HCC: an overview and update. Infect Agent Cancer. 2017;12:23. https://doi.org/10.1186/s13027-017-0132-y.

68. Granata V, Faggioni L, Grassi R, Fusco R, Reginelli A, Rega D, Maggialetti N, Buccicardi D, Frittoli B, Rengo M, Bortolotto C, Prost R, Lacasella GV, Montella M, Ciaghi E, Bellifemine F, De Muzio F, Grazzini G, De Filippo M, Cappabianca S, Laghi A, Grassi R, Brunese L, Neri E, Miele V, Coppola F. Structured reporting of computed tomography in the staging of colon cancer: a Delphi consensus proposal. Radiol Med. 2022;127(1):21-9. https://doi.org/10.1007/s11547-021-01418-9.

69. Cellini F, Di Franco R, Manfrida S, Borzillo V, Maranzano E, Pergolizzi S, Morganti AG, Fusco V, Deodato F, Santarelli M, Arcidiacono F, Rossi R, Reina S, Merlotti A, Jereczek-Fossa BA, Tozzi A, Siepe G, Cacciola A, Russi E, Gambacorta MA, Scorsetti M, Ricardi U, Corvò R, Donato V, Muto P, Valentini V. Palliative radiotherapy indications during the COVID19 pandemic and in future complex logistic settings: the normality model. Radiol Med. 2021;126(12):1619-56. https://doi.org/10.1007/ s11547-021-01414-z.

70. Fusco R, Granata V, Maio F, Sansone M, Petrillo A. Textural radiomic featuresand time-intensity curve data analysis by dynamic contrastenhanced MRI for early prediction of breast cancer therapy response: preliminary data. Eur Radiol Exp. 2020;4(1):8. https://doi.org/10.1186/ s41747-019-0141-2.

71. Fusco R, Raiano N, Raiano C, Maio F, Vallone P, Mattace Raso M, Setola SV, Granata V, Rubulotta MR, Barretta ML, Petrosino T, Petrillo A. Evaluation of average glandular dose and investigation of the relationship with compressed breast thickness in dual energy contrast enhanced digital mammography and digital breast tomosynthesis. Eur J Radiol. 2020;126:108912. https://doi.org/10.1016/j.ejrad.2020.108912.

72. Petrillo A, Fusco R, Vallone P, Filice S, Granata V, Petrosino T, Rosaria Rubulotta M, Setola SV, Mattace Raso M, Maio F, Raiano C, Siani C, Di Bonito M, Botti G. Digital breast tomosynthesis and contrast-enhanced dual-energy digital mammography alone and in combination compared to 2D digital synthetized mammography and MR imaging in breast cancer detection and classification. Breast J. 2020;26(5):860-72. https://doi.org/10.1111/tbj.13739.

73. Mayerhoefer ME, Szomolanyi P, Jirak D, Berg A, Materka A, Dirisamer A, et al. Effects of magnetic resonance image interpolation on the results of texture- based pattern classification: a phantom study. Investig Radiol. 2009;44(7):405-11. https://doi.org/10.1097/RLI.0b013e3181 a50a66.

74. Barile A. Correction to: Some thoughts and greetings from the new Editor-in-Chief. Radiol Med. 2021;126(10):1377. https://doi.org/10.1007/ s11547-021-01346-8 (Erratum for: Radiol Med. 2021; 126(1):3-4).

75. Mirabile A, Lucarelli NM, Sollazzo EP, Stabile lanora AA, Sardaro A, Mirabile G, Lorusso F, Racanelli V, Maggialetti N, Scardapane A. CT pulmonary angiography appropriateness in a single emergency department: does the use of revised Geneva score matter? Radiol Med. 2021;126(12):1544-52. https://doi.org/10.1007/s11547-021-01416-х.

76. Materka A, Strzelecki M, Lerski R, Schad L. Evaluation of texture features of test objects for magnetic resonance imaging. In: Pietikainen $M$, editor. Infotech Oulu workshop on texture analysis in machine vision. Oulu: FInfotech; 1999. p. 13-9.

77. Materka A, Strzelecki M. Texture analysis methods: a review. Inst Electron Tech Univ Lodz, Poland. 1998;11:1-32.

78. Kovalev VA, Krugge F, Gertz HJ, Von Cramon DY. Three-dimensional texture analysis of MRI brain datasets. IEEE Trans Med Imaging. 2001;20(5):424-33. https://doi.org/10.1109/42.925295.

79. Mahmoud-Ghoneim D, Toussaint G, Constans JM, de Certaines JD. Threedimensional texture analysis in MRI: a preliminary evaluation in gliomas. Magn Reson Imaging. 2003;21(9):983-7. https://doi.org/10. 1016/50730-725X(03)00201-7.

80. Woods BJ, Clymer BD, Kurc T, Heverhagen JT, Stevens R, Orsdemir A, et al. Malignant-lesion segmentation using $4 \mathrm{D}$ co-occurrence texture analysis applied to dynamic contrast-enhanced magnetic resonance breast image data. J Magn Reson Imaging. 2007;25(3):495-501. https:// doi.org/10.1002/jmri.20837.

81. Nakata N. Recent technical development of artificial intelligence for diagnostic medical imaging. Jpn J Radiol. 2019;37(2):103-8. https://doi. org/10.1007/s11604-018-0804-6.

82. Koc A, Sezgin OS, Kayipmaz S. Comparing different planimetric methods on volumetric estimations by using cone beam computed 
tomography. Radiol Med. 2020;125(4):398-405. https://doi.org/10.1007/ s11547-019-01131-8.

83. Neri E, Miele V, Coppola F, Grassi R. Use of CT and artificial intelligence in suspected or COVID-19 positive patients: statement of the Italian society of medical and interventional radiology. Radiol Med. 2020;125:505-8.

84. Caruso D, Polici M, Zerunian M, Pucciarelli F, Polidori T, Guido G, Rucci C, Bracci B, Muscogiuri E, De Dominicis C, Laghi A. Quantitative Chest CT analysis in discriminating COVID-19 from non-COVID-19 patients. Radiol Med. 2021;126(2):243-9.

85. Neri E, Coppola F, Miele V, Bibbolino C, Grassi R. Artificial intelligence: Who is responsible for the diagnosis? Radiol Med. 2020;125(6):517-21. https://doi.org/10.1007/s11547-020-01135-9.

86. van Assen M, Muscogiuri G, Caruso D, Lee SJ, Laghi A, De Cecco $\mathrm{CN}$. Artificial intelligence in cardiac radiology. Radiol Med. 2020;125(11):1186-99. https://doi.org/10.1007/s11547-020-01277-w.

87. Granata V, Grassi R, Fusco R, Galdiero R, Setola SV, Palaia R, Belli A, Silvestro L, Cozzi D, Brunese L, Petrillo A, Izzo F. Pancreatic cancer detection and characterization: state of the art and radiomics. Eur Rev Med Pharmacol Sci. 2021;25(10):3684-99. https://doi.org/10.26355/eurrev_ 202105_25935 (PMID: 34109578).

88. Parmar C, Grossmann P, Bussink J, Lambin P, Aerts HJ. Machine learning methods for quantitative radiomic biomarkers. Sci Rep. 2015;5:13087.

89. Rizzo S, Botta F, Raimondi S, Origgi D, Buscarino V, Colarieti A, Tomao F, Aletti G, Zanagnolo V, Del Grande M, Colombo N, Bellomi M. Radiomics of high-grade serous ovarian cancer: association between quantitative CT features, residual tumour and disease progression within 12 months. Eur Radiol. 2018;28(11):4849-59. https://doi.org/10.1007/ s00330-018-5389-z.

90. Huynh E, Coroller TP, Narayan V, et al. Associations of radiomic data extracted from static and respiratory-gated $\mathrm{CT}$ scans with disease recurrence in lung cancer patients treated with SBRT. PLOS ONE. 2017;12:e0169172.

91. Wilkinson L, Friendly M. The history of the cluster heat map. Am Stat. 2009:63:179-84.

92. Jolliffe IT. Principal component analysis, series: Springer series in statistics. 2nd ed. New York: Springer; 2002. p. 487.

93. Barabino M, Gurgitano M, Fochesato C, Angileri SA, Franceschelli G, Santambrogio R, Mariani NM, Opocher E, Carrafiello G. LI-RADS to categorize liver nodules in patients at risk of HCC: tool or a gadget in daily practice? Radiol Med. 2021;126(1):5-13. https://doi.org/10.1007/ s11547-020-01225-8.

94. Cholangiocarcinoma Working Group. Italian clinical practice guidelines on cholangiocarcinoma-Part I: classification, diagnosis and staging. Dig Liver Dis. 2020;52(11):1282-93. https://doi.org/10.1016/j.dld.2020. 06.045.

95. Cholangiocarcinoma Working Group. Italian clinical practice guidelines on cholangiocarcinoma - Part II: treatment. Dig Liver Dis. 2020;52(12):1430-42. https://doi.org/10.1016/j.dld.2020.08.030.

96. Patrone R, Izzo F, Palaia R, Granata V, Nasti G, Ottaiano A, Pasta G, Belli A. Minimally invasive surgical treatment of intrahepatic cholangiocarcinoma: a systematic review. World J Gastrointest Oncol. 2021;13(12):2203-15. https://doi.org/10.4251/wjgo.v13.i12.2203.

97. Gabelloni M, Di Nasso M, Morganti R, Faggioni L, Masi G, Falcone A, Neri E. Application of the ESR iGuide clinical decision support system to the imaging pathway of patients with hepatocellular carcinoma and cholangiocarcinoma: preliminary findings. Radiol Med. 2020;125(6):531-7. https://doi.org/10.1007/s11547-020-01142-w.

98. Granata V, Grassi R, Fusco R, Setola SV, Belli A, Ottaiano A, Nasti G, La Porta M, Danti G, Cappabianca S, Cutolo C, Petrillo A, Izzo F. Intrahepatic cholangiocarcinoma and its differential diagnosis at MRI: how radiologist should assess MR features. Radiol Med. 2021;126(12):1584-600. https://doi.org/10.1007/s11547-021-01428-7.

99. Gatti M, Calandri M, Bergamasco L, Darvizeh F, Grazioli L, Inchingolo R, Ippolito D, Rousset S, Veltri A, Fonio P, Faletti R. Characterization of the arterial enhancement pattern of focal liver lesions by multiple arterial phase magnetic resonance imaging: comparison between hepatocellular carcinoma and focal nodular hyperplasia. Radiol Med. 2020;125(4):348-55. https://doi.org/10.1007/s11547-019-01127-4.

100. Orlacchio A, Chegai F, Roma S, Merolla S, Bosa A, Francioso S. Degradable starch microspheres transarterial chemoembolization (DSMs-TACE) in patients with unresectable hepatocellular carcinoma (HCC): long-term results from a single-center 137-patient cohort prospective study. Radiol Med. 2020;125(1):98-106. https://doi.org/10.1007/ s11547-019-01093-x.

101. Argalia G, Tarantino G, Ventura C, Campioni D, Tagliati C, Guardati P, Kostandini A, Marzioni M, Giuseppetti GM, Giovagnoni A. Shear wave elastography and transient elastography in HCV patients after directacting antivirals. Radiol Med. 2021;126:894-9. https://doi.org/10.1007/ s11547-020-01326-4 (Epub ahead of print. PMID: 33492651).

102. De Filippo M, Ziglioli F, Russo U, Pagano P, Brunese L, Bertelli E, Pagnini F, Maestroni U. Radiofrequency ablation (RFA) of T1a renal cancer with externally cooled multitined expandable electrodes. Radiol Med. 2020;125(8):790-7. https://doi.org/10.1007/s11547-020-01175-1.

103. Arrigoni F, Bruno F, Gianneramo C, Palumbo P, Zugaro L, Zoccali C, Barile A, Masciocchi C. Evolution of the imaging features of osteoid osteoma treated with RFA or MRgFUS during a long-term follow-up: a pictorial review with clinical correlations. Radiol Med. 2020;125(6):578-84. https://doi.org/10.1007/s11547-020-01134-w.

104. Agostini A, Borgheresi A, Mari A, Floridi C, Bruno F, Carotti M, Schicchi N, Barile A, Maggi S, Giovagnoni A. Dual-energy CT: theoretical principles and clinical applications. Radiol Med. 2019;124(12):1281-95. https://doi. org/10.1007/s11547-019-01107-8.

105. Park SH, Kim YS, Choi J. Dosimetric analysis of the effects of a temporary tissue expander on the radiotherapy technique. Radiol Med. 2021;126(3):437-44. https://doi.org/10.1007/s11547-020-01297-6.

106. Nakamura Y, Higaki T, Honda Y, Tatsugami F, Tani C, Fukumoto W, Narita $\mathrm{K}$, Kondo S, Akagi M, Awai K. Advanced CT techniques for assessing hepatocellular carcinoma. Radiol Med. 2021;126(7):925-35. https://doi. org/10.1007/s11547-021-01366-4

107. Hu HT, Shan QY, Chen SL, Li B, Feng ST, Xu EJ, Li X, Long JY, Xie XY, Lu MD, Kuang M, Shen JX, Wang W. CT-based radiomics for preoperative prediction of early recurrent hepatocellular carcinoma: technical reproducibility of acquisition and scanners. Radiol Med. 2020;125(8):697-705. https://doi.org/10.1007/s11547-020-01174-2.

108. Choi JW, Kim H, Kim HC, et al. Blood oxygen level-dependent MRI for evaluation of early response of liver tumors to chemoembolization: an animal study. Anticancer Res. 2013;33:1887-92.

109. Boldrini L, Cusumano D, Chiloiro G, Casà C, Masciocchi C, Lenkowicz J, Cellini F, Dinapoli N, Azario L, Teodoli S, Gambacorta MA, De Spirito M, Valentini V. Delta radiomics for rectal cancer response prediction with hybrid $0.35 \mathrm{~T}$ magnetic resonance-guided radiotherapy (MRgRT): a hypothesis-generating study for an innovative personalized medicine approach. Radiol Med. 2019;124(2):145-53. https://doi.org/10.1007/ s11547-018-0951-y.

110. Nazari M, Shiri I, Hajianfar G, Oveisi N, Abdollahi H, Deevband MR, Oveisi $\mathrm{M}$, Zaidi $\mathrm{H}$. Noninvasive Fuhrman grading of clear cell renal cell carcinoma using computed tomography radiomic features and machine learning. Radiol Med. 2020;125(8):754-62. https://doi.org/10.1007/ s11547-020-01169-z.

111. Borhani AA, Catania R, Velichko YS, Hectors S, Taouli B, Lewis S. Radiomics of hepatocellular carcinoma: promising roles in patient selection, prediction, and assessment of treatment response. Abdom Radiol (NY). 2021. https://doi.org/10.1007/s00261-021-03085-w.

112. Sagir KA. Radiomics in hepatocellular carcinoma. J Gastrointest Cancer. 2020:51(4):1165-8. https://doi.org/10.1007/s12029-020-00493-x.

113. Zhong X, Guan T, Tang D, Li J, Lu B, Cui S, Tang H. Differentiation of small $(\leq 3 \mathrm{~cm})$ hepatocellular carcinomas from benign nodules in cirrhotic liver: the added additive value of MRI-based radiomics analysis to LI-RADS version 2018 algorithm. BMC Gastroenterol. 2021;21 (1):155. https://doi.org/10.1186/s12876-021-01710-y.

114. Jiang H, Liu X, Chen J, Wei Y, Lee JM, Cao L, Wu Y, Duan T, Li X, Ma L, Song B. Man or machine? Prospective comparison of the version 2018 EASL, LI-RADS criteria and a radiomics model to diagnose hepatocellular carcinoma. Cancer Imaging. 2019;19(1):84. https://doi.org/10.1186/ s40644-019-0266-9.

115. Mokrane FZ, Lu L, Vavasseur A, Otal P, Peron JM, Luk L, Yang H, Ammari S, Saenger Y, Rousseau H, Zhao B, Schwartz LH, Dercle L. Radiomics machine-learning signature for diagnosis of hepatocellular carcinoma in cirrhotic patients with indeterminate liver nodules. Eur Radiol. 2020;30(1):558-70. https://doi.org/10.1007/s00330-019-06347-w. 
116. Houseni M, Mahmoud MA, Saad S, ElHussiny F, Shihab M. Advanced intra-tumoural structural characterisation of hepatocellular carcinoma utilising FDG-PET/CT: a comparative study of radiomics and metabolic features in 3D and 2D. Pol J Radiol. 2021;86:e64-73. https://doi.org/10. 5114/pjr.2021.103239.

117. Maruyama H, Yamaguchi T, Nagamatsu H, Shiina S. Al-based radiological imaging for HCC: current status and future of ultrasound. Diagnostics (Basel). 2021;11(2):292. https://doi.org/10.3390/diagnostics1102 0292 (PMID: 33673229; PMCID: PMC7918339).

118. Yao Z, Dong Y, Wu G, Zhang Q, Yang D, Yu JH, Wang WP. Preoperative diagnosis and prediction of hepatocellular carcinoma: Radiomics analysis based on multi-modal ultrasound images. BMC Cancer. 2018;18(1):1089. https://doi.org/10.1186/s12885-018-5003-4.

119. Lai Q, Spoletini G, Mennini G, Laureiro ZL, Tsilimigras DI, PawlikTM, Rossi M. Prognostic role of artificial intelligence among patients with hepatocellular cancer: a systematic review. World J Gastroenterol. 2020;26(42):6679-88. https://doi.org/10.3748/wjg.v26.i42.6679.

120. Chen Y, Liu Z, Mo Y, Li B, Zhou Q, Peng S, Li S, Kuang M. Prediction of post-hepatectomy liver failure in patients with hepatocellular carcinoma based on radiomics using Gd-EOB-DTPA-enhanced MRI: the liver failure model. Front Oncol. 2021;11:605296. https://doi.org/10.3389/ fonc.2021.605296.

121. Zhang L, Hu J, Hou J, Jiang X, Guo L, Tian L. Radiomics-based model using gadoxetic acid disodium-enhanced MR images: associations with recurrence-free survival of patients with hepatocellular carcinoma treated by surgical resection. Abdom Radiol (NY). 2021. https://doi.org/ 10.1007/s00261-021-03034-7.

122. Kuang Y, Li R, Jia P, Ye W, Zhou R, Zhu R, Wang J, Lin S, Pang P, Ji W. MRI-based radiomics: nomograms predicting the short-term response after transcatheter arterial chemoembolization (TACE) in hepatocellular carcinoma patients with diameter less than $5 \mathrm{~cm}$. Abdom Radiol (NY). 2021. https://doi.org/10.1007/s00261-021-02992-2.

123. Chen M, Cao J, Hu J, Topatana W, Li S, Juengpanich S, Lin J, Tong C, Shen J, Zhang B, Wu J, Pocha C, Kudo M, Amedei A, Trevisani F, Sung PS, Zaydfudim VM, Kanda T, Cai X. Clinical-radiomic analysis for pretreatment prediction of objective response to first transarterial chemoembolization in hepatocellular carcinoma. Liver Cancer. 2021;10(1):38-51. https://doi.org/10.1159/000512028.

124. Jin Z, Chen L, Zhong B, Zhou H, Zhu H, Zhou H, Song J, Guo J, Zhu $X$, Ji J, Ni C, Teng G. Machine-learning analysis of contrast-enhanced computed tomography radiomics predicts patients with hepatocellular carcinoma who are unsuitable for initial transarterial chemoembolization monotherapy: a multicenter study. Transl Oncol. 2021;14(4): 101034. https://doi.org/10.1016/j.tranon.2021.101034.

125. Niu XK, He XF. Development of a computed tomography-based radiomics nomogram for prediction of transarterial chemoembolization refractoriness in hepatocellular carcinoma. World J Gastroenterol. 2021;27(2):189-207. https://doi.org/10.3748/wjg.v27.i2.189.

126. Yuan G, Song Y, Li Q, Hu X, Zang M, Dai W, Cheng X, Huang W, Yu W, Chen M, Guo Y, Zhang Q, Chen J. Development and validation of a contrast-enhanced CT-based radiomics nomogram for prediction of therapeutic efficacy of anti-PD-1 antibodies in advanced HCC patients. Front Immunol. 2021;11:613946. https://doi.org/10.3389/fimmu.2020. 613946.

127. Ma QP, He XL, Li K, Wang JF, Zeng QJ, Xu EJ, He XQ, Li SY, Kun W, Zheng $R Q$, Tian J. Dynamic contrast-enhanced ultrasound radiomics for hepatocellular carcinoma recurrence prediction after thermal ablation. Mol Imaging Biol. 2021. https://doi.org/10.1007/s11307-021-01578-0.

128. Wu K, Shui Y, Sun W, Lin S, Pang H. Utility of radiomics for predicting patient survival in hepatocellular carcinoma with portal vein tumor thrombosis treated with stereotactic body radiotherapy. Front Oncol. 2020;10:569435. https://doi.org/10.3389/fonc.2020.569435.

129. Nie P, Yang G, Guo J, Chen J, Li X, Ji Q, Wu J, Cui J, Xu W. A CT-based radiomics nomogram for differentiation of focal nodular hyperplasia from hepatocellular carcinoma in the non-cirrhotic liver. Cancer Imaging. 2020;20:20.

130. Wu J, Liu A, Cui J, Chen A, Song Q, Xie L. Radiomics-based classification of hepatocellular carcinoma and hepatic hemangioma on precontrast magnetic resonance images. BMC Med Imaging. 2019;19:23.

131. Liang W, Shao J, Liu W, Ruan S, Tian W, Zhang X, Wan D, Huang Q, Ding $Y$, Xiao W. Differentiating hepatic epithelioid angiomyolipoma from hepatocellular carcinoma and focal nodular hyperplasia via radiomics models. Front Oncol. 2020;10:564307.

132. Mokrane FZ, Lu L, Vavasseur A, Otal P, Peron JM, Luk L, Yang H, Ammari $\mathrm{S}$, Saenger $Y$, Rousseau H, et al. Radiomics machine-learning signature for diagnosis of hepatocellular carcinoma in cirrhotic patients with indeterminate liver nodules. Eur Radiol. 2020;30:558-70.

133. Cellina M, Pirovano M, Ciocca M, Gibelli D, Floridi C, Oliva G. Radiomic analysis of the optic nerve at the first episode of acute optic neuritis: an indicator of optic nerve pathology and a predictor of visual recovery? Radiol Med. 2021;126(5):698-706. https://doi.org/10.1007/ s11547-020-01318-4.

134. Granata V, Fusco R, Venanzio Setola S, Sandomenico F, Luisa Barretta M, Belli A, Palaia R, Tatangelo F, Grassi R, Izzo F, Petrillo A. Major and ancillary features according to LI-RADS in the assessment of combined hepatocellular-cholangiocarcinoma. Radiol Oncol. 2020;54(2):149-58. https://doi.org/10.2478/raon-2020-0029.

135. Granata V, Fusco R, Setola SV, Picone C, Vallone P, Belli A, Incollingo P, Albino V, Tatangelo F, Izzo F, Petrillo A. Microvascular invasion and grading in hepatocellular carcinoma: correlation with major and ancillary features according to LIRADS. Abdom Radiol (NY). 2019;44(8):2788-800. https://doi.org/10.1007/s00261-019-02056-6.

136. Oyama A, Hiraoka Y, Obayashi I, Saikawa Y, Furui S, Shiraishi K, Kumagai S, Hayashi T, Kotoku J. Hepatic tumor classification using texture and topology analysis of non-contrast-enhanced three-dimensional T1-weighted MR images with a radiomics approach. Sci Rep. 2019;9(1):8764. https://doi.org/10.1038/s41598-019-45283-Z.

137. Li Z, Mao Y, Huang W, Li H, Zhu J, Li W, Li B. Texture-based classification of different single liver lesion based on SPAIR T2W MRI images. BMC Med Imaging. 2017;17(1):42. https://doi.org/10.1186/ s12880-017-0212-x.

138. Jansen MJA, Kuijf HJ, Veldhuis WB, Wessels FJ, Viergever MA, Pluim JPW. Automatic classification of focal liver lesions based on MRI and risk factors. PLOS ONE. 2019;14(5):e0217053. https://doi.org/10.1371/journ al.pone.0217053.

139. Gatos I, Tsantis S, Karamesini M, Spiliopoulos S, Karnabatidis D, Hazle JD, et al. Focal liver lesions segmentation and classification in nonenhanced T2-weighted MRI. Med Phys. 2017:44(3):3695-705.

140. Chu H, Liu Z, Liang W, Zhou Q, Zhang Y, Lei K, Tang M, Cao Y, Chen S, Peng S, Kuang M. Radiomics using CT images for preoperative prediction of futile resection in intrahepatic cholangiocarcinoma. Eur Radiol. 2021;31(4):2368-76. https://doi.org/10.1007/s00330-020-07250-5.

141. Qin H, Hu X, Zhang J, Dai H, He Y, Zhao Z, Yang J, Xu Z, Hu X, Chen Z. Machine-learning radiomics to predict early recurrence in perihilar cholangiocarcinoma after curative resection. Liver Int. 2021;41(4):83750. https://doi.org/10.1111/liv.14763 (Epub 2020 Dec 25).

142. Hao X, Liu B, Hu X, Wei J, Han Y, Liu X, Chen Z, Li J, Bai J, Chen Y, Wang J, Niu M, Tian J. A radiomics-based approach for predicting early recurrence in intrahepatic cholangiocarcinoma after surgical resection: a multicenter study. Annu Int Conf IEEE Eng Med Biol Soc. 2021;2021:3659-62. https://doi.org/10.1109/EMBC46164.2021.9630029.

143. Tang Y, Zhang T, Zhou X, Zhao Y, Xu H, Liu Y, Wang H, Chen Z, Ma X. The preoperative prognostic value of the radiomics nomogram based on CT combined with machine learning in patients with intrahepatic cholangiocarcinoma. World J Surg Oncol. 2021;19(1):45. https://doi.org/ 10.1186/s12957-021-02162-0.

144. Li MD, Lu XZ, Liu JF, Chen B, Xu M, Xie XY, Lu MD, Kuang M, Wang W, Shen $\mathrm{SL}$, Chen LD. Preoperative survival prediction in intrahepatic cholangiocarcinoma using a ultrasound-based radiographic-radiomics signature. J Ultrasound Med. 2021. https://doi.org/10.1002/jum.15833.

145. Park HJ, Park B, Park SY, Choi SH, Rhee H, Park JH, Cho ES, Yeom SK, Park S, Park MS, Lee SS. Preoperative prediction of postsurgical outcomes in mass-forming intrahepatic cholangiocarcinoma based on clinical, radiologic, and radiomics features. Eur Radiol. 2021;31(11):8638-48. https://doi.org/10.1007/s00330-021-07926-6.

146. King MJ, Hectors S, Lee KM, Omidele O, Babb JS, Schwartz M, Tabrizian P, Taouli B, Lewis S. Outcomes assessment in intrahepatic cholangiocarcinoma using qualitative and quantitative imaging features. Cancer Imaging. 2020;20(1):43. https://doi.org/10.1186/s40644-020-00323-0.

147. Xiang F, Wei S, Liu X, Liang X, Yang L, Yan S. Radiomics analysis of contrast-enhanced CT for the preoperative prediction of microvascular 
invasion in mass-forming intrahepatic cholangiocarcinoma. Front Oncol. 2021;11:774117. https://doi.org/10.3389/fonc.2021.774117.

148. Liang W, Xu L, Yang P, Zhang L, Wan D, Huang Q, Niu T, Chen F. Novel nomogram for preoperative prediction of early recurrence in intrahepatic cholangiocarcinoma. Front Oncol. 2018;8:360. https://doi.org/10 3389/fonc.2018.00360.

149. Ji GW, Zhu FP, Zhang YD, Liu XS, Wu FY, Wang K, Xia YX, Zhang YD, Jiang WJ, Li XC, Wang XH. A radiomics approach to predict lymph node metastasis and clinical outcome of intrahepatic cholangiocarcinoma. Eur Radiol. 2019;29(7):3725-35. https://doi.org/10.1007/ s00330-019-06142-7.

150. Mosconi C, Cucchetti A, Bruno A, Cappelli A, Bargellini I, De Benedittis C, Lorenzoni G, Gramenzi A, Tarantino FP, Parini L, Pettinato V, Modestino F, Peta G, Cioni R, Golfieri R. Radiomics of cholangiocarcinoma on pretreatment $C T$ can identify patients who would best respond to radioembolisation. Eur Radiol. 2020;30(8):4534-44. https://doi.org/10. 1007/s00330-020-06795-9.

151. Xu H, Zou X, Zhao Y, Zhang T, Tang Y, Zheng A, Zhou X, Ma X. Differentiation of intrahepatic cholangiocarcinoma and hepatic lymphoma based on radiomics and machine learning in contrastenhanced computer tomography. Technol Cancer Res Treat. 2021;20:15330338211039124. https://doi.org/10.1177/1533033821 1039125.

152. Peng YT, Zhou CY, Lin P, Wen DY, Wang XD, Zhong XZ, Pan DH, Que $Q$, $\mathrm{Li} X$, Chen L, He Y, Yang H. Preoperative ultrasound radiomics signatures for noninvasive evaluation of biological characteristics of intrahepatic cholangiocarcinoma. Acad Radiol. 2020;27(6):785-97. https://doi.org/ 10.1016/j.acra.2019.07.029.

153. Deng L, Chen B, Zhan C, Yu H, Zheng J, Bao W, Deng T, Zheng C, Wu L, Yang Y, Yu Z, Wang Y, Chen G. A novel clinical-radiomics model based on sarcopenia and radiomics for predicting the prognosis of intrahepatic cholangiocarcinoma after radical hepatectomy. Front Oncol. 2021;11:744311. https://doi.org/10.3389/fonc.2021.744311.

154. Li Q, Che F, Wei Y, Jiang HY, Zhang Y, Song B. Role of noninvasive imaging in the evaluation of intrahepatic cholangiocarcinoma: from diagnosis and prognosis to treatment response. Expert Rev Gastroenterol Hepatol. 2021;15(11):1267-79. https://doi.org/10.1080/17474124. 2021.1974294.

155. Zhang J, Wu Z, Zhang X, Liu S, Zhao J, Yuan F, Shi Y, Song B. Machine learning: an approach to preoperatively predict PD-1/PD-L1 expression and outcome in intrahepatic cholangiocarcinoma using MRI biomarkers. ESMO Open. 2020;5(6):e000910. https://doi.org/10.1136/esmoo pen-2020-000910.

156. Xue B, Wu S, Zheng $M$, Jiang $H$, Chen J, Jiang Z, Tian T, Tu Y, Zhao H, Shen X, Ramen K, Wu X, Zhang Q, Zeng Q, Zheng X. Development and validation of a radiomic-based model for prediction of intrahepatic cholangiocarcinoma in patients with intrahepatic lithiasis complicated by imagologically diagnosed mass. Front Oncol. 2021;10:598253. https://doi.org/10.3389/fonc.2020.598253.

157. Xu L, Wan Y, Luo C, Yang J, Yang P, Chen F, Wang J, Niu T. Integrating intratumoral and peritumoral features to predict tumor recurrence in intrahepatic cholangiocarcinoma. Phys Med Biol. 2021;66(12):125001. https://doi.org/10.1088/1361-6560/ac01f3.

158. Wang Y, Shao J, Wang P, Chen L, Ying M, Chai S, Ruan S, Tian W, Cheng $Y$, Zhang $H$, Zhang $X$, Wang $X$, Ding Y, Liang W, Wu L. Deep learning radiomics to predict regional lymph node staging for hilar cholangiocarcinoma. Front Oncol. 2021;11:721460. https://doi.org/10.3389/fonc. 2021.721460

159. Tang Y, Yang CM, Su S, Wang WJ, Fan LP, Shu J. Machine learningbased radiomics analysis for differentiation degree and lymphatic node metastasis of extrahepatic cholangiocarcinoma. BMC Cancer. 2021;21(1):1268. https://doi.org/10.1186/s12885-021-08947-6.

160. Zhao J, Zhang W, Zhu YY, Zheng HY, Xu L, Zhang J, Liu SY, Li FY, Song B. Development and validation of noninvasive MRI-based signature for preoperative prediction of early recurrence in perihilar cholangiocarcinoma. J Magn Reson Imaging. 2021. https://doi.org/10.1002/jmri.27846.

161. Yao X, Huang X, Yang C, Hu A, Zhou G, Ju M, Lei J, Shu J. Correction: A novel approach to assessing differentiation degree and lymph node metastasis of extrahepatic cholangiocarcinoma: prediction using a radiomics-based particle swarm optimization and support vector machine model. JMIR Med Inform. 2021;9(1):e25337. https://doi.org/10.2196/ 25337 (Erratum for: JMIR Med Inform. 2020 Oct 5;8(10):e23578).

162. Silva M, Maddalo M, Leoni E, Giuliotti S, Milanese G, Ghetti C, Biasini E, De Filippo M, Missale G, Sverzellati N. Integrated prognostication of intrahepatic cholangiocarcinoma by contrast-enhanced computed tomography: the adjunct yield of radiomics. Abdom Radiol (NY). 2021;46(10):4689-700. https://doi.org/10.1007/s00261-021-03183-9 (Epub 2021 Jun 24).

163. Ren S, Li Q, Liu S, Qi Q, Duan S, Mao B, Li X, Wu Y, Zhang L. Clinical value of machine learning-based ultrasomics in preoperative differentiation between hepatocellular carcinoma and intrahepatic cholangiocarcinoma: a multicenter study. Front Oncol. 2021;11:749137. https://doi. org/10.3389/fonc.2021.749137.

164. Xue B, Wu S, Zhang M, Hong J, Liu B, Xu N, Zeng Q, Tang K, Zheng X. $A$ radiomic-based model of different contrast-enhanced $C T$ phase for differentiate intrahepatic cholangiocarcinoma from inflammatory mass with hepatolithiasis. Abdom Radiol (NY). 2021;46(8):3835-44. https:// doi.org/10.1007/s00261-021-03027-6.

165. Zhao L, Ma X, Liang M, Li D, Ma P, Wang S, Wu Z, Zhao X. Prediction for early recurrence of intrahepatic mass-forming cholangiocarcinoma: quantitative magnetic resonance imaging combined with prognostic immunohistochemical markers. Cancer Imaging. 2019;19(1):49. https:// doi.org/10.1186/s40644-019-0234-4.

166. Aherne EA, Pak LM, Goldman DA, Gonen M, Jarnagin WR, Simpson AL, Do RK. Intrahepatic cholangiocarcinoma: can imaging phenotypes predict survival and tumor genetics? Abdom Radiol (NY). 2018;43(10):2665-72. https://doi.org/10.1007/s00261-018-1505-4.

\section{Publisher's Note}

Springer Nature remains neutral with regard to jurisdictional claims in published maps and institutional affiliations.

Ready to submit your research? Choose BMC and benefit from:

- fast, convenient online submission

- thorough peer review by experienced researchers in your field

- rapid publication on acceptance

- support for research data, including large and complex data types

- gold Open Access which fosters wider collaboration and increased citations

- maximum visibility for your research: over $100 \mathrm{M}$ website views per year

At BMC, research is always in progress.

Learn more biomedcentral.com/submissions 